\title{
PRODUÇÃO E RENDA BRUTA DE RÚCULA (Eruca sativa Mill.) 'CULTIVADA' E DE ALMEIRÃO (CIchorium intybus L.) 'AMARELO' EM CULTIVOSOLTEIROE CONSORCIADO ${ }^{1}$
}

\author{
Yield and gross income of 'Cultivada' roquette (Eruca sativa Mill) and 'Amarelo' \\ chicory (Cichorium intybus L.) in mono-cropping and intercropping system
}

\author{
Wilmara Corrêa Harder², Néstor Antonio Heredia Zárate², Maria do Carmo Vieira²
}

\begin{abstract}
RESUMO
O trabalho foi desenvolvido em Dourados-MS, para avaliar a produção e a renda bruta da rúcula 'Cultivada'-R e do almeirão 'Amarelo'-A, cultivados solteiros sob três linhas $\left(\mathrm{R}_{3}\right.$ e $\left.\mathrm{A}_{3}\right)$ e quatro linhas $\left(\mathrm{R}_{4}\right.$ e $\left.\mathrm{A}_{4}\right)$, e nos consórcios $\mathrm{R}_{4} \mathrm{~A}_{3}$ e $\mathrm{R}_{3} \mathrm{~A}_{4}$, arranjados no delineamento experimental de blocos casualizados, com cinco repetições. Foram realizadas colheitas aos 52 dias após o semeio e aos 35 dias após a primeira colheita. Na rúcula e no almeirão, respectivamente, a altura de plantas (26,54 e 24,99 cm), o número de folhas por planta $\left(23,4\right.$ e 16,40), o comprimento $(18,62$ e $24,68 \mathrm{~cm})$ e a área de uma folha $\left(66,73\right.$ e $\left.177,0 \mathrm{~cm}^{2}\right)$ não foram influenciados significativamente pelo número de linhas nem pelo consórcio, mas foram maiores na primeira, em relação à segunda colheita. $\mathrm{O}$ comprimento da folha de almeirão foi influenciado significativamente pela interação tipo de cultivo e número de linhas por canteiro, com variação de $22,74 \mathrm{~cm}$ no $R_{4}$ até $26,78 \mathrm{~cm}$ no $R_{3} A_{4}$. A produção de massa fresca $\left(15,66\right.$ e $\left.11,62 \mathrm{t} \mathrm{ha}^{-1}\right)$ e seca $\left(1,33\right.$ e $\left.1,00 \mathrm{t} \mathrm{ha}{ }^{-1}\right)$ de rúcula foram significativamente diferentes sob quatro e três linhas de plantas, respectivamente. No almeirão, as matérias fresca e

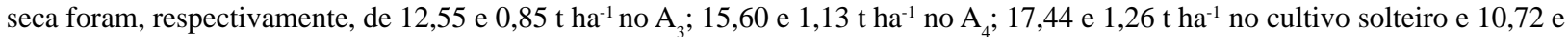
$0,72 \mathrm{t} \mathrm{ha}^{-1}$ no consórcio. A razão de área equivalente (RAE), para a primeira e segunda colheita, foi de 1,87 e 1,76 para $\mathrm{R}_{3} \mathrm{~A}_{4}$ e 1,56 e 1,58 para $R_{4} A_{3}$ respectivamente. $O$ arranjo $R_{4} A_{3}$ poderia ter gerado incrementos monetários por hectare de $R \$ 28.279,80$ e de $\mathrm{R}$ \$ 20.065,95 na primeira colheita e $\mathrm{R} \$ 18.703,35$ e de $\mathrm{R} \$ 17.283,60$ na segunda colheita, em relação ao almeirão e a rúcula solteira. A melhor renda bruta na segunda colheita foi no tratamento $R_{4} A_{3}$, correspondendo a $84,27 \%$ da melhor renda bruta obtida na primeira colheita, no mesmo tratamento, em ciclo vegetativo 17 dias menor.
\end{abstract}

Termos para indexação: Cichorium intybus L., Eruca sativa Mill., associação de culturas, produtividade, renda bruta.

\begin{abstract}
The work was carried out in Dourados - MS, with the objective of evaluating yield and gross income in mono-cropping and inter-cropping system. Mono-croppings of 'Cultivada' roquette-R and 'Amarelo' chicory- $A$, in three rows $\left(A_{3}\right)$ and four $\left(A_{4}\right)$ rows and $\mathrm{R}_{3} \mathrm{~A}_{4}$ and $\mathrm{R}_{4} \mathrm{~A}_{3}$ intercropping systems were studied in randomized block design, with five replications. Harvests were done at 52 days after sowing and at 35 days after the first harvest. For roquette and chicory, respectively, plant heights $(26.54$ and $24.99 \mathrm{~cm})$, number of leaves per plant (23.4 and 16.40), length $(18.62$ and $24.68 \mathrm{~cm})$ and area of one leaf $\left(66.73\right.$ and $\left.177.0 \mathrm{~cm}^{2}\right)$ were not influenced by number of rows, neither by intercropping system, but results were greater for the first harvest than the second. Length of chicory leaf was significantly influenced by intercropped system and number of rows interaction, which ranged from 22.74 ( $\left.\mathrm{R}_{4}\right)$ up to $26.78 \mathrm{~cm}\left(\mathrm{R}_{3} \mathrm{~A}_{4}\right)$. Yield of fresh (15.66 and $\left.11.62 \mathrm{tha}^{-1}\right)$ and dried $\left(1.33\right.$ and $\left.1.00 \mathrm{t} \mathrm{ha}^{-1}\right)$ mass of roquette under four and three rows were significantly different, respectively. Fresh and dried matter of chicory treatments were, respectively, 12.55 and $0.85 \mathrm{t} \mathrm{ha}^{-1}$ for $\mathrm{A}_{3}, 15.60$ and $1.13 \mathrm{t} \mathrm{ha}^{-1}$ for $\mathrm{A}_{4}, 17.44$ and $1.26 \mathrm{t} \mathrm{ha}^{-1}$ under mono-cropping system and 10.72 and $0.72 \mathrm{t} \mathrm{ha}^{-1}$ under intercropping system. LER for the first and the second harvests were 1.87 and 1.76 for $R_{3} A_{4}$ and 1.56 and 1.58 for $R_{4} A_{3}$, respectively. $R_{4} A_{3}$ arrangement could have produced monetary increases of $\mathrm{R} \$ 28,279.80$ and $\mathrm{R} \$ 20,065.60$ for the second harvest, regarding to roquette and chicory. The best gross income for the second harvest was in $\mathrm{R}_{4} \mathrm{~A}_{3}$ treatment, with corresponded to $87 \%$ of the best gross income of the first harvest for the same treatment, with a shorter 17-day vegetative cycle.
\end{abstract}

Index terms: Cichorium intybus L.; Eruca sativa Mill, intercropping, productivity, income.

(Recebido para publicação em 22 de julho de 2004 e aprovado em 23 de março de 2005)

\section{INTRODUÇÃO}

A busca por alternativas no setor produtivo abriu portas para que o conhecimento agrícola indígena venha a ser estudado e compreendido. Estudos sobre consorciação de culturas estão contribuindo para o encontro de futuros caminhos para a agricultura tradicional e para que se descubra o quão mais avançada pode ser a tecnologia da consorciação em relação ao monocultivo, quanto à sustentabilidade do ambiente, mediante a manutenção da biodiversidade, conservação do solo, reciclagem de nutrientes, controle de plantas daninhas, controle de pragas e doenças e aumento da produtividade (INNIS, 1997).

${ }_{1}$ Parte da dissertação do primeiro autor apresentada ao Curso de Mestrado em Agronomia/UFMS.

${ }^{2}$ Professores UFMS/DCA - Caixa Postal 533 - 79804-970 - Dourados-MS - Bolsistas de Produtividade em Pesquisa do CNPq - nheredia@ceud.ufms.br 
A produção agrícola é o resultado da ação integrada da planta e dos estímulos do meio ambiente, enquanto a produção consorciada é a interação entre culturas diferentes em condições necessárias para o seu desenvolvimento (SULLIVAN, 2003). A associação/ consorciação de culturas é um sistema de cultivo utilizado há séculos pelos agricultores (MÜLLER et al., 1998) e é praticado amplamente nas regiões tropicais (SRINIVASAN \& AHLAWAT, 1990), principalmente entre pequenos produtores. Innis (1997) relata que, os principais consórcios são: nas Américas, a combinação de milho (Zea mays L.) e feijão (Phaseolus vulgaris L); na África, do milheto (Pennisetum glaucum L.) e feijão-caupi (Vigna unguiculata L.); no Leste Europeu, o trigo (Triticum aestivum L.) e grão-de-bico (Cicer arietinum L.); na Índia, o sorgo (Sorghum spp L.) e feijão andu (Cajanus cajan L.); na China, o arroz (Oryza sativa L.) e soja (Glycine max L.) e na Europa usam-se a aveia (Avena sativa L.), ervilha (Pisum sativum L.), cevada (Hordeum vulgare L.) e feijão.

No Brasil, segundo (SILVA, 1983), pequenos agricultores geralmente cultivam diversas espécies associadas às de milho, cana-de-açúcar, café e outras. Na região de Campos, RJ, na cultura da cana-de-açúcar, muitas vezes é feito intercultivo de abóbora, milho e feijão. Em Goiânia, com finalidade de sombreamento, foi observado um caso de utilização de consórcio de couve comum com alface e cenoura, cultivadas em canteiro cuja margem, voltada para o sol da tarde, cultivava-se uma linha de couve. Em casos como esse, o objetivo do consórcio não é a obtenção de maior produtividade, mas a melhoria da qualidade comercial do produto. A consorciação tem despertado a atenção de inúmeros pesquisadores, os quais vêm estudando aspectos desse sistema cultural, como arranjo, densidade e época de semeadura das culturas, fertilização e identificação de cultivares mais adaptados (CAETANO et al., 1999; INNIS, 1997; SALVADOR, 2003; TOLENTINO JÚNIOR et al., 2002; VIEIRA, 1989; VIEIRA et al., 2003).

Na literatura consultada, não foram encontrados relatos sobre o consórcio de Cichorium intybus L. (almeirão) com Eruca sativa Mill. (rúcula), plantas que apresentam hábitos de crescimento semelhantes e períodos de maturação próximos. Santamaria et al. (1998) citam que o almeirão (Cichorium intybus L.) é uma planta herbácea perene, da família Asteraceae, usada como hortaliça de folhas, como raiz tuberosa ou como pastagem. Além disso, pode ser usada a raiz seca e moída como chá, em substituição e ou como suplemento para o café. Na Itália, cerca de 16.000 hectares são cultivados com diferentes cultivares de almeirão. As folhas de materiais selvagens também são usadas comumente na alimentação humana, em saladas ou cozidas É uma planta muito semelhante à chicória (Cichorium endivia L.) e se diferencia por possuir folhas mais alongadas, mais estreitas, recobertas por pêlos e com sabor amargo mais pronunciado (FILGUEIRA, 2000). As cultivares mais plantadas no Brasil são Folha Larga, Branca e Pão-de- Açúcar (CAMARGO, 1992). Santamaria et al. (1998) relatam que, sob o nome de "rúcula" são agrupadas grande número de espécies da família Brassicaceae que apresentam sabor picante, principalmente Eruca sativa Mill. A popularidade da rúcula como cultura é devida ao sabor picante de suas folhas, que são usadas em guarnição de saladas, petiscos e grande variedade de pratos. A semente é utilizada como fonte de óleo na Índia e na tradicional fitoterapia, com vários propósitos.

Kunelius \& McRae (1998) cultivaram almeirão 'Puna' em consórcio com pastagens e leguminosas, e observaram que as menores produções de massa seca e fresca foram obtidas para o monocultivo de almeirão. Salvador (2003), estudando a produtividade e a renda bruta da cebolinha (C) 'Todo Ano' e do almeirão (Al) 'Folha Larga', em cultivo solteiro e consorciado, relata que sob consórcio houve aumento de $9,79 \mathrm{~cm}$ na altura da planta de cebolinha. O número de folhas por planta do almeirão foi maior com três linhas no cultivo solteiro e com quatro no consórcio. As RAEs, para as produtividades de massa fresca das espécies, cultivadas sob os respectivos números de linhas, foram de 1,93 para $\mathrm{C}_{3} \mathrm{Al}_{4}$ (três linhas de cebolinha e quatro linhas de almeirão) e de 1,59 para $\mathrm{C}_{4} \mathrm{Al}_{3}$ (quatro linhas de cebolinha e três linhas de almeirão).

Conduziu-se este trabalho com o objetivo de avaliar a capacidade produtiva e a renda bruta da rúcula e do almeirão, sob cultivo solteiro e consorciado.

\section{MATERIALEMÉTODOS}

O experimento foi conduzido em área do Horto de Plantas Medicinais, do Núcleo Experimental de Ciências Agrárias, da Universidade Federal do Mato Grosso do Sul, em Dourados-MS, entre março e junho de 2003. O município de Dourados situa-se em latitude de $22^{\circ} 13^{\prime} 16^{\prime \prime S}$, longitude de $54^{\circ} 17^{\prime} 01^{\prime \prime} \mathrm{W}$ e altitude de $430 \mathrm{~m}$. O clima da região, segundo a classificação de Köppen, é Mesotérmico Úmido; do tipo Cwa, com temperaturas e precipitações médias anuais variando de $20^{\circ}$ a $24^{\circ} \mathrm{C}$ e de $1250 \mathrm{~mm}$ a 1500 $\mathrm{mm}$, respectivamente. O solo é do tipo Latossolo Vermelho distroférrico, com as seguintes características químicas: 6,0 de pH em água; 35,53 $\mathrm{g} \mathrm{dm}^{-3}$ de M.O; 40,23 $\mathrm{mg} \mathrm{dm}^{-3} \mathrm{de}$ $\mathrm{P} ; 0,43 ; 4,80 ; 2,63 ; 12,63$ e 7,86 $\mathrm{cmol}_{\mathrm{c}} \mathrm{dm}^{-3}$ de $\mathrm{K}, \mathrm{Ca}, \mathrm{Mg}$,

Ciênc. agrotec., Lavras, v. 29, n. 4, p. 775-785, jul./ago., 2005 
CTC e Soma de bases, respectivamente, e $62,33 \%$ de Saturação de bases.

As espécies estudadas foram almeirão ‘Amarelo’A e rúcula 'Cultivada'-R, como culturas solteiras, com três e quatro linhas de plantas, e consorciadas (Figura 1), arranjadas no delineamento experimental de blocos casualizados, com cinco repetições. As parcelas tiveram área total de $2,25 \mathrm{~m}^{2}$ (1,5 $\mathrm{m}$ de largura por $1,5 \mathrm{~m}$ de comprimento), sendo que a largura efetiva do canteiro foi $1,08 \mathrm{~m}$. Utilizaram-se espaçamentos para as culturas solteiras de $0,10 \mathrm{~m}$ entre plantas e de 0,36 m entre linhas para as linhas triplas e de 0,27 m entre linhas para as linhas quádruplas. No consórcio, os espaçamentos foram de 0,27 m entre linhas para cada espécie.

O terreno foi preparado com trator, duas semanas antes da semeadura, com uma aração e uma gradagem e, posteriormente, foram levantados os canteiros com rotoencanteiradora. Para a semeadura, que foi manual, foram abertos sulcos de dois centímetros de largura e um centímetro de profundidade. A semeadura foi manual, colocando-se três ou quatro sementes por cova.
Posteriormente, as sementes foram cobertas com camade-aviário semidecomposta. Quinze dias após a emergência, fez-se o desbaste para deixar uma planta por cova. As irrigações foram feitas utilizando o sistema de aspersão, sendo que na fase inicial, até as plantas apresentarem em torno de 0,10 m de altura, os turnos de rega foram diários e, posteriormente, a cada dois dias. Durante o ciclo da cultura foram feitas capinas com enxada, entre os canteiros, e manualmente, nos canteiros. Não houve infestações de pragas ou infecção por doenças.

Foram realizadas duas colheitas, sendo a primeira aos 52 dias após a semeadura e a segunda, correspondente à rebrota, aos 35 dias após a primeira, quando as folhas das plantas das duas espécies apresentavam perda do brilho, como indicativo do ponto de colheita. Antes de cada colheita, foram medidas as alturas das plantas por parcela, desde o nível do solo até a inflexão da folha, utilizando-se régua graduada em centímetros. A colheita da rúcula consistiu no corte das folhas acima das brotações novas, em torno de dois centímetros de altura, e a do

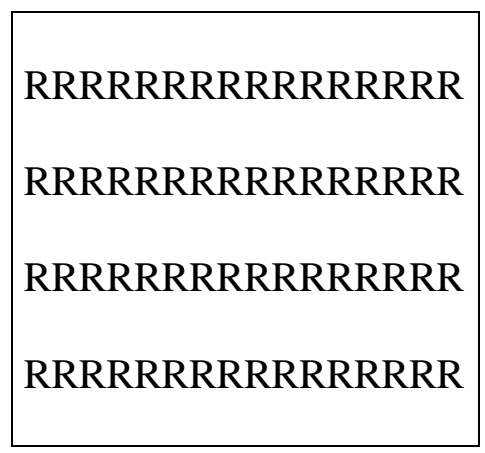

Rúcula solteira $\left(\mathbf{R}_{4}\right)$

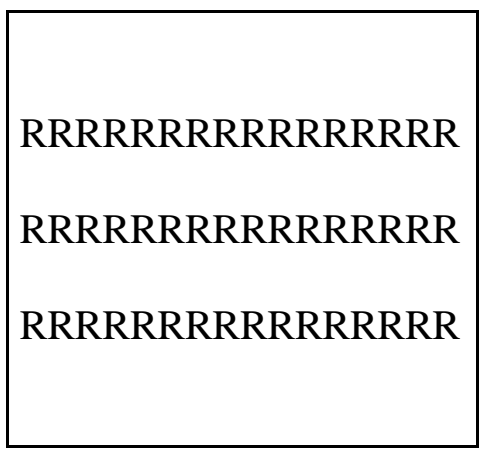

Rúcula solteira $\left(\mathbf{R}_{3}\right)$

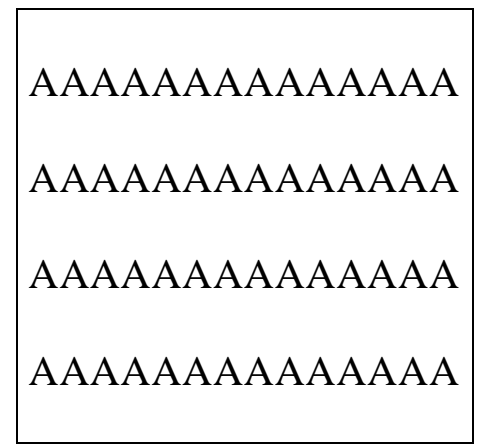

Almeirão solteiro $\left(\mathbf{A}_{4}\right)$

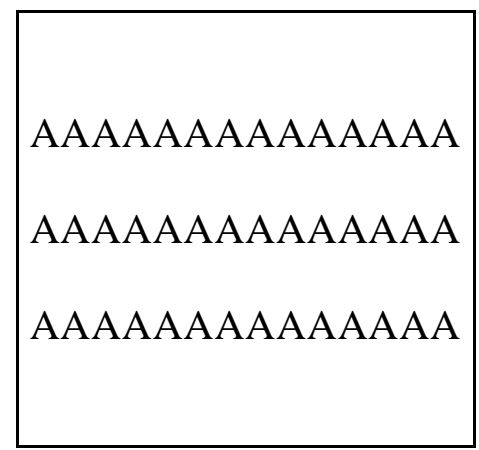

Almeirão solteiro ( $\left(\mathbf{A}_{3}\right)$

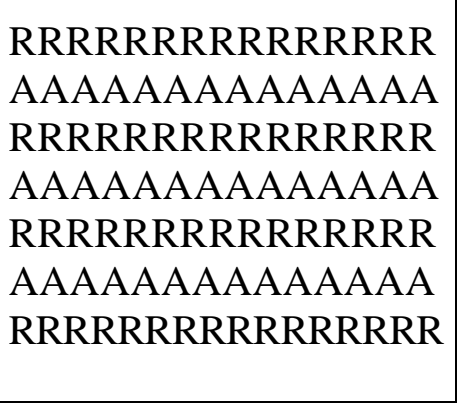

Consórcio $\mathbf{R}_{4} \mathbf{A}_{3}$

AAAAAAAAAAAAAA

RRRRRRRRRRRRRRR

AAAAAAAAAAAAAA

RRRRRRRRRRRRRRR

AAAAAAAAAAAAAA

RRRRRRRRRRRRRRR

AAAAAAAAAAAAAA

FIGURA 1 - Arranjo de plantas de rúcula (R) e de almeirão (A), como culturas solteiras, com três ou quatro linhas de plantas por canteiro, e consorciadas. Dourados, UFMS, 2003. 
almeirão consistiu no corte das folhas ao nível do solo. Nas duas colheitas foram separadas cinco plantas por parcela para cada espécie, e no laboratório, foram determinados: número de folhas por planta, comprimento de folhas e área foliar de uma folha. $O$ restante das plantas, de cada parcela, foi pesado e somado aos pesos das outras plantas.

O número de folhas por planta foi determinado pela contagem das folhas das cinco plantas e classificadas em tamanhos pequeno, médio e grande, exceto as folhas amareladas e em estádio de putrefação. O comprimento médio das folhas foi aferido em amostra de duas folhas para cada classe, totalizando seis folhas por parcela. Posterior à medição das seis folhas de cada parcela, as mesmas foram lavadas, em água corrente, e deixadas secar ao ar livre para depois serem submetidas à medição da área foliar, com integrador eletrônico LICOR 3000. A massa fresca foi avaliada mediante a pesagem das folhas de todas as plantas de cada parcela, após a retirada do campo. Aproximadamente $500 \mathrm{~g}$ de massa fresca de folhas por parcela foi deixada em balcões ao ar livre, durante dois dias, com o objetivo de eliminar parte da umidade. Após esse período, as folhas foram cortadas, acondicionadas em sacos de papel e colocadas em estufa à temperatura média de $60^{\circ} \pm 2^{\circ}$ até atingirem massa constante, para avaliação da massa seca de folhas.

Os dados foram submetidos à análise de variância e quando detectou-se diferenças significativas entre os tratamentos, aplicou-se o teste de Tukey, a 5\% de probabilidade. O consórcio foi avaliado utilizando a metodologia proposta por Caetano et al. (1999), sendo: $\mathrm{RAE}=\mathrm{Ac} \cdot \mathrm{As}^{-1}+\mathrm{Rc} \cdot \mathrm{Rs}^{-1}$, em que Ac e Rc significam a produção das parcelas consorciadas de almeirão e rúcula, respectivamente, e As e Rs, a produção das parcelas em monocultivo. A validação do consórcio foi realizada pela determinação da renda bruta, por cultivo e total, utilizando os preços pagos ao produtor de Dourados-MS. Para isso, foram comprados três maços de almeirão e três de rúcula em um supermercado, e determinadas as massas frescas (variação de 405,0 a 505,0 g e média de 448,3 g para almeirão e de 225,0 a 235,0 g e média de 231,7 g para rúcula). Segundo os vendedores, o preço pago aos produtores foi de $\mathrm{R} \$ 0,45$ por maço de almeirão ou de rúcula. Posteriormente, efetuaram-se as conversões por hectare para número de maços e renda bruta, por cultivo e total, para o produtor.

\section{RESULTADOS E DISCUSSÃO}

As alturas médias das plantas e o número médio de folhas por planta de rúcula (26,54 cm e 23,40 folhas) e de almeirão (24,99 cm e 16,49 folhas) não foram influenciados significativamente pelo número de linhas nem pelo consórcio, mas foram maiores na primeira, em relação à segunda colheita (Tabelas 1 e 2). Para a altura das plantas e número de folhas por planta de rúcula, observou-se diferença de $11,50 \mathrm{~cm}$ e 9,58 folhas, respectivamente, entre a primeira e a segunda colheita; no almeirão, as diferenças foram de 4,8 cm e 5,27 folhas por planta. Esses resultados permitem supor que as relações fonte-dreno podem ser alteradas pelas condições de cultivo e pelas diferenças no estádio fisiológico das culturas. Esse fato se confirma com a diminuição da altura das plantas das duas espécies, na segunda colheita, quando as folhas que se desenvolveram após o corte das plantas podem ter respondido diferencialmente à competição por luz (WHATLEY \& WHATLEY, 1982), altura do corte ou porque tiveram menor tempo para se desenvolver e, conseqüentemente, para produzir e translocar fotoassimilados (LARCHER, 2000).

As alturas das plantas obtidas nas primeira e segunda colheita, neste experimento, foram semelhantes àquelas citadas por Novo et al. (2003) para as cultivares 'Folha Larga' (35,58 cm), 'Pão-de-açúcar' (28,68 cm) e 'Catalonha' (38,87 cm). Também mostraram semelhança com os resultados obtidos por Salvador (2003), ao estudar o consórcio de almeirão e cebolinha, o qual observou que não houve diferença significativa para altura de plantas de almeirão, as quais variaram entre $30,3 \mathrm{~cm}$ para cultivo solteiro e $33,8 \mathrm{~cm}$ para cultivo sob consórcio.

O período de 52 dias entre a semeadura e a primeira colheita e de 35 dias para a segunda colheita são coerentes com os períodos citados na literatura e indicam que as plantas de almeirão tiveram tempo suficiente para se desenvolverem, porém, não foram capazes de compensar a diferença da altura de corte ou de outros fatores que induziram a perda do vigor inicial das plantas. Clark et al. (1990) citados por Kunelius \& McRae (1998), perceberam que intervalos de corte das plantas de almeirão de quatro semanas, com altura de corte de $10 \mathrm{~cm}$, resultaram em alta relação limbo/pecíolo e alta produtividade, não prejudicando a rebrota. A altura de corte de $10 \mathrm{~cm}$ poderia viabilizar uma rebrota mais vigorosa, mas, mostrou-se inviável de ser executada em função do mercado consumidor nacional demandar folhas inteiras no momento da compra.

O comprimento e a área de uma folha de rúcula (Tabela 3) e a área foliar do almeirão (Tabela 4) não foram influenciados significativamente pelos fatores em estudo. Isso indica que os sistemas vegetais são capazes de se auto-regular, baseando-se na capacidade de adaptação do

Ciênc. agrotec., Lavras, v. 29, n. 4, p. 775-785, jul./ago., 2005 
TABELA 1 - Altura da planta e número de folhas por planta de rúcula, cultivadas sob três e quatro linhas por canteiro, em cultivo solteiro e consorciado, na primeira e segunda colheita. Dourados, UFMS, 2003.

\begin{tabular}{|c|c|c|c|c|c|c|}
\hline \multirow[t]{2}{*}{$\begin{array}{l}\text { Número de linhas } \\
\text { no canteiro }\end{array}$} & \multicolumn{3}{|c|}{$\begin{array}{l}\text { Altura da planta }(\mathrm{cm}) \\
\text { Colheita }\end{array}$} & \multicolumn{3}{|c|}{$\begin{array}{l}\text { Número de folhas planta } \\
\text { Colheita }\end{array}$} \\
\hline & $\mathbf{1}^{\mathbf{a}}$ & $2^{\mathbf{a}}$ & Média & $1^{\mathbf{a}}$ & $2^{\mathrm{a}}$ & Média \\
\hline 3 & 31,39 & 21,04 & 26,22 & 27,68 & 18,90 & 23,29 \\
\hline 4 & 33,18 & 20,53 & 26,86 & 28,70 & 18,32 & 23,51 \\
\hline \multicolumn{7}{|l|}{ Tipo de Cultivo } \\
\hline Solteiro & 31,62 & 20,56 & 26,09 & 27,82 & 19,80 & 23,81 \\
\hline Consórcio & 32,95 & 21,01 & 26,98 & 28,56 & 17,42 & 22,99 \\
\hline Média & $32,29 \mathrm{a}^{\mathrm{a}^{\prime}}$ & $20,79 \mathrm{~b}$ & 26,54 & 28,19 a & $18,61 \mathrm{~b}$ & 23,40 \\
\hline C.V. $(\%)$ & & & 10,20 & & & 24,50 \\
\hline
\end{tabular}

$\underline{1}$ / F, $5 \%$ de probabilidade.

TABELA 2 - Altura da planta e número de folhas por planta de almeirão, cultivadas sob três e quatro linhas por canteiro, em cultivo solteiro e consorciado, na primeira e segunda colheita. Dourados, UFMS, 2003.

\begin{tabular}{|c|c|c|c|c|c|c|}
\hline \multirow{3}{*}{$\begin{array}{l}\text { Número de linhas } \\
\text { no canteiro }\end{array}$} & \multicolumn{3}{|c|}{ Altura da planta $(\mathrm{cm})$} & \multicolumn{3}{|c|}{ Número de folhas planta ${ }^{-1}$} \\
\hline & \multicolumn{3}{|c|}{ Colheita } & \multicolumn{3}{|c|}{ Colheita } \\
\hline & $\mathbf{1}^{\mathbf{a}}$ & $2^{\mathrm{a}}$ & Média & $1^{\mathrm{a}}$ & $2^{\mathrm{a}}$ & Média \\
\hline 3 & 27,24 & 21,30 & 24,27 & 19,58 & 14,22 & 16,90 \\
\hline 4 & 27,48 & 23,88 & 25,68 & 18,66 & 13,48 & 16,07 \\
\hline \multicolumn{7}{|l|}{ Tipo de Cultivo } \\
\hline Solteiro & 26,38 & 22,93 & 24,66 & 19,64 & 14,5 & 17,07 \\
\hline Consórcio & 28,39 & 22,24 & 25,32 & 18,6 & 13,2 & 15,90 \\
\hline Média & $27,39 \mathrm{a}^{1 /}$ & $22,59 \mathrm{~b}$ & 24,99 & $19,12 \mathrm{a}$ & $13,85 \mathrm{~b}$ & 16,49 \\
\hline C.V. $(\%)$ & & & 10,10 & & & 24,40 \\
\hline
\end{tabular}

1/F, $5 \%$ de probabilidade.

organismo individual e das populações (LARCHER, 2000), relacionado às diferenças no crescimento e desenvolvimento das plantas, de cada espécie, até alcançar o ponto de colheita (TOLENTINO JÚNIOR et al., 2002).

Em relação às épocas de colheita, observou-se que os valores da área foliar, nas duas espécies, foram significativamente maiores na primeira colheita (Tabelas 3 e 4). Esses resultados mostram que houve diferenças na provável capacidade de auto-regulação das plantas em relação ao equilíbrio das relações de interferência (LARCHER, 2000) que, no caso da segunda colheita, é relacionada com a reação das plantas ao corte feito, para 
obter a primeira colheita.

O comprimento da folha de almeirão foi influenciado significativamente pela interação tipo de cultivo e número de linhas por canteiro (Tabela 5). O maior comprimento médio foi observado para o arranjo $\mathrm{R}_{3} \mathrm{~A}_{4}$ (três linhas de rúcula e quatro linhas de almeirão) e o menor para as plantas sob quatro linhas e cultivo solteiro. Esses resultados mostram coerência com a citação de Sullivan (2003) de que, uma das razões mais importantes para se cultivar duas ou mais culturas juntas é o aumento da produtividade por unidade de área. Para tanto, devem ser considerados o arranjo espacial e a densidade das plantas, dentre outros, visando proporcionar maximização da cooperação e minimização da competição entre as espécies. De um modo geral, nos sistemas consorciados, os recursos são explorados ao máximo; a água, luz, dióxido de carbono e nutrientes do solo são usados mais racionalmente (SILVA, 1983).

TABELA 3 - Comprimento e área foliar de uma folha de rúcula, cultivadas sob três e quatro linhas por canteiro, em cultivo solteiro e consorciado, na primeira e segunda colheita. Dourados, UFMS, 2003.

\begin{tabular}{|c|c|c|c|c|c|c|}
\hline \multirow{3}{*}{$\begin{array}{l}\text { Número de linhas } \\
\text { no canteiro }\end{array}$} & \multicolumn{3}{|c|}{ Comprimento da folha $(\mathrm{cm})$} & \multicolumn{3}{|c|}{ Área foliar $\left(\mathrm{cm}^{2}\right.$ folha $\left.{ }^{-1}\right)$} \\
\hline & \multicolumn{3}{|c|}{ Colheita } & \multicolumn{3}{|c|}{ Colheita } \\
\hline & $\mathbf{1}^{\mathbf{a}}$ & $2^{\mathrm{a}}$ & Média & $1^{\mathbf{a}}$ & $2^{\underline{a}}$ & Média \\
\hline 3 & 22,82 & 15,15 & 18,99 & 101,68 & 37,39 & 69,54 \\
\hline 4 & 21,13 & 15,34 & 18,24 & 97,98 & 30,04 & 64,01 \\
\hline \multicolumn{7}{|l|}{ Tipo de Cultivo } \\
\hline Solteiro & 21,46 & 15,52 & 18,49 & 97,96 & 36,76 & 67,36 \\
\hline Consórcio & 22,5 & 14,97 & 18,74 & 101,7 & 30,67 & 66,19 \\
\hline Média & $21,98 \mathrm{a}^{\mathbf{1}^{\prime /}}$ & $15,25 \mathrm{~b}$ & 18,62 & $99,83 \mathrm{a}$ & $33,72 \mathrm{~b}$ & 66,73 \\
\hline C.V.(\%) & & & 14,70 & & & 20,40 \\
\hline
\end{tabular}

1/ F, $5 \%$ de probabilidade.

TABELA 4 - Comprimento e área de uma folha de almeirão, cultivadas sob três e quatro linhas por canteiro, em cultivo solteiro e consorciado, na primeira e segunda colheita. Dourados, UFMS, 2003.

\begin{tabular}{|c|c|c|c|c|c|c|}
\hline \multirow{3}{*}{$\begin{array}{l}\text { Número de linhas } \\
\text { no canteiro }\end{array}$} & \multicolumn{3}{|c|}{ Comprimento da folha $(\mathrm{cm})$} & \multicolumn{3}{|c|}{ Área foliar $\left(\mathrm{cm}^{2}\right.$ folha $\left.{ }^{-1}\right)$} \\
\hline & \multicolumn{3}{|c|}{ Colheita } & \multicolumn{3}{|c|}{ Colheita } \\
\hline & $\mathbf{1}^{\mathrm{a}}$ & $2^{\mathbf{a}}$ & Média & $\mathbf{1}^{\mathbf{a}}$ & $2^{\mathbf{a}}$ & Média \\
\hline 3 & 24,65 & 24,53 & 24,59 & 224,69 & 111,43 & 168,06 \\
\hline 4 & 24,09 & 25,43 & 24,76 & 230,81 & 141,07 & 185,94 \\
\hline \multicolumn{7}{|l|}{ Tipo de Cultivo } \\
\hline Solteiro & 22,93 & 24,58 & $23,76 \mathrm{~b}^{\underline{1}}$ & 237,21 & 134,56 & 185,89 \\
\hline Consórcio & 25,81 & 25,36 & $25,59 \mathrm{a}$ & 218,29 & 117,94 & 168,12 \\
\hline Média & 24,37 & 24,97 & 24,68 & $227,75 \mathrm{~A}$ & $126,25 \mathrm{~B}$ & 177,00 \\
\hline CV $(\%)$ & & & 10,60 & & & 26,30 \\
\hline
\end{tabular}

Ciênc. agrotec., Lavras, v. 29, n. 4, p. 775-785, jul./ago., 2005 
TABELA 5 - Comprimento da folha das plantas de almeirão em função da interação número de linhas por canteiro e forma de cultivo. Dourados, UFMS, 2003.

\begin{tabular}{cccc}
\hline $\begin{array}{c}\text { Número de linhas } \\
\text { por canteiro }\end{array}$ & \multicolumn{3}{c}{ Forma de cultivo } \\
\cline { 2 - 3 } & Solteiro & Consórcio \\
\hline 3 & $24,79 \mathrm{a}^{\underline{1}}$ & $24,39 \mathrm{a}$ \\
4 & $22,74 \mathrm{a}$ & & $26,78 \mathrm{~b}$ \\
\hline
\end{tabular}

1/ Médias seguidas por letras diferentes minúsculas nas linhas, diferem pelo teste $\mathrm{F}$, a $5 \%$ de probabilidade.

As variações dos comprimentos das folhas de almeirão de tamanho pequeno, médio e grande, respectivamente, nas parcelas sob cultivo solteiro, foram de 9,0 a 20,$5 ; 18,5$ a 31,0 e 25,5 a $38,0 \mathrm{~cm}$ para três linhas; 6,0 a 21,0; 18,5 a 30,0 e 24,0 a $45,0 \mathrm{~cm}$ para quatro linhas. Para rúcula, os valores foram de 7,6 a 16,6; 8,0 a 25,5 e 11,0 a 37,2 cm para três linhas e de 7,5 a 15,6; 10,0 a 26,0 e 11,0 a 37,0 $\mathrm{cm}$ para quatro linhas. Nas parcelas com consórcio, para almeirão, as variações foram de 7,0 a 23,0; 20,0 a 31,5 e 26,5 a 49,4 cm para três linhas e de 10,4 a 22,0; 20,9 a 38,8 e 28,4 a 49,6 cm para quatro linhas; para rúcula, as variações foram de 4,0 a 18,$8 ; 8,0$ a 29,8 e 11,0 a $42,5 \mathrm{~cm}$ para três linhas e de 4,0 a 14,9; 9,0 a 24,6 e 12,5 a $36,8 \mathrm{~cm}$ para quatro linhas. Por esses resultados, concluiu-se que o comprimento das folhas é uma característica intrínseca da espécie e dependente da forma de condução da cultura (HEREDIAZÁRATE et al., 1999). Isso porque, as maiores magnitudes e menores amplitudes de variação dos comprimentos das folhas foram observadas nas plantas do almeirão sob consórcio; o contrário foi observado nas plantas de rúcula.

As produções de massa fresca e massa seca das plantas de rúcula apresentaram efeito significativo apenas para o número de linhas por canteiro. A produção sob quatro linhas (15,66 e 1,33 tha-1) de plantas teve aumento de 4,04 e $0,33 \mathrm{tha}^{-1} \mathrm{em}$ relação à das cultivadas sob três linhas $\left(11,62\right.$ e 1,00 $\left.\mathrm{t} \mathrm{ha}^{-1}\right)$, para massa fresca e seca, respectivamente (Tabela 6). Isso porque a maximização da produção depende da população empregada em função da capacidade suporte do meio e do sistema de produção adotado (BÜLL, 1993) e da adequada distribuição espacial das plantas na área, em conformidade com as características genotípicas.

No almeirão, as produções de massa fresca e seca foram influenciadas significativamente pelo número de linhas por canteiro e pelo sistema de cultivo (Tabela 7). As diferenças produtivas de massa fresca e seca, respectivamente, foram 3,05 e $0,28 \mathrm{t} \mathrm{ha}^{-1}$ entre quatro e três linhas e 6,72 e 0,54 t ha ${ }^{-1}$ entre monocultivo e o consórcio. Esses resultados indicam que houve melhor adaptabilidade das plantas cultivadas sob quatro linhas e em cultivo solteiro, provavelmente relacionadas com a manutenção da eficiência na absorção ou no uso da água, dos nutrientes e do $\mathrm{CO}_{2}$, já que, na maioria dos casos, nas culturas consorciadas é notada redução da produtividade (SILVA, 1983).

As plantas de rúcula não apresentaram boa capacidade de reação ao corte, feito na primeira colheita, o que pode ser notado pela diminuição da produção de massa fresca e massa seca na segunda colheita (Tabela 6) sendo observado o inverso para o almeirão (Tabela 7). As plantas podem apresentar taxas de crescimento e morfologia bem características, em razão de fatores ambientais, mas com padrão de resposta dependente do componente genético (HEREDIA ZÁRATE, 1988). Os resultados obtidos para massa seca de almeirão foram semelhantes aos dos estudos feitos por Kunelius \& McRae (1998) sobre a persistência do almeirão em consórcio com gramíneas de inverno e leguminosas, em que obtiveram produção de 1,9;2,3 e 2,3 $\mathrm{t} \mathrm{ha}^{-1}$ de massa seca em plantio solteiro para o primeiro, segundo e terceiro cortes anuais, respectivamente. Mas, foram diferentes aos obtidos no consórcio com capimcornichão, em que a produção de massa seca do almeirão foi de 0,70 e $0,63 \mathrm{t} \mathrm{ha}^{-1}$ para o primeiro e o terceiro ano, respectivamente.

A razão de área equivalente (RAE), para o consórcio de rúcula sob três linhas e de almeirão sob quatro linhas $\left(\mathrm{R}_{3} \mathrm{~A}_{4}\right)$, considerando as produtividades de massa fresca das culturas, foi de $1,87\left[\operatorname{RAE} \mathrm{R}_{3} \mathrm{~A}_{4}=(14,20,11,62)+\right.$ $(11,71,18,01)=1,22+0,65=1,87]$ na primeira colheita (Tabela 8) e 1,76 [RAER ${ }_{3} A_{4}=(11,06,9,60)+(12,41,20,25)$ $=1,15+0,61=1,76]$ na segunda (Tabela 9). Para o consórcio rúcula sob quatro linhas e de almeirão sob três linhas $\left(\mathrm{R}_{4} \mathrm{~A}_{3}\right)$, foi de $1,56\left[\operatorname{RAER}_{4} \mathrm{~A}_{3}=(17,45,18,37)+(8,71,14,30)=0,95\right.$ 
$+0,61=1,56]$ na primeira colheita e $1,58\left[\right.$ RAE $_{4} \mathrm{~A}_{3}=(13,31$ $, 13,51)+(10,04,17,16)=0,99+0,59=1,58]$ na segunda. Pelo fato de os valores da RAEs terem sido superiores a 1,0 , nas duas colheitas, conclui-se que os consórcios entre a rúcula e o almeirão foram efetivos e podem ser recomendados.

As RAEs obtidas foram próximas daquelas observadas por vários autores para outras espécies de hortaliças consorciadas. Salvador (2003) obteve RAE de 1,59 e 1,93 no consórcio cebolinha e almeirão cultivados nos arranjos quatro linhas de cebolinha e três linhas de almeirão $\left(\mathrm{C}_{4} \mathrm{~A}_{3}\right)$ e três linhas de cebolinha e quatro linhas de almeirão, respectivamente $\left(\mathrm{C}_{3} \mathrm{~A}_{4}\right)$. Caetano et al. (1999), no consórcio alface e cenoura, obtiveram RAE de 1,74 em 1995 e de 1,76 em 1996. Já Gliessman (1999) cita variação das RAEs de 1,10 - 1,36 observadas no consórcio alface e brócoli, em três densidades de cultivo. Heredia Zárate et al. (2003) obtiveram RAEs de 1,41 e 1,50 para o consórcio cebolinha 'Todo Ano' e salsa 'Lisa', ao considerar as produtividades de massas frescas e secas, respectivamente.

TABELA 6 - Produção de massa fresca e seca das plantas de rúcula, cultivadas sob três e quatro linhas por canteiro, em cultivo solteiro e consorciado, na primeira e segunda colheitas. Dourados, UFMS, 2003.

\begin{tabular}{|c|c|c|c|c|c|c|}
\hline \multirow{3}{*}{$\begin{array}{l}\text { Número de linhas } \\
\text { por canteiro }\end{array}$} & \multicolumn{3}{|c|}{ Massa Fresca $\left(\mathrm{t} \mathrm{ha}^{-1}\right)$} & \multicolumn{3}{|c|}{ Massa Seca $\left(t\right.$ ha $\left.^{-1}\right)$} \\
\hline & \multicolumn{3}{|c|}{ Colheita } & \multicolumn{3}{|c|}{ Colheita } \\
\hline & $1^{\mathbf{a}}$ & $2^{\mathrm{a}}$ & Média & $1^{-\mathbf{a}}$ & $2^{\mathrm{a}}$ & Média \\
\hline 3 & 12,91 & 10,33 & $11,62 b^{1 / /}$ & 1,03 & 0,97 & $1,00 \mathrm{~b}$ \\
\hline 4 & 17,91 & 13,41 & $15,66 \mathrm{a}$ & 1,46 & 1,20 & $1,33 \mathrm{a}$ \\
\hline \multicolumn{7}{|l|}{ Tipo de cultivo } \\
\hline Solteiro & 14,99 & 11,56 & 13,28 & 1,29 & 1,04 & 1,17 \\
\hline Consórcio & 15,82 & 12,19 & 14,01 & 1,20 & 1,13 & 1,17 \\
\hline Média & $15,41 \mathrm{~A}$ & $11,88 \mathrm{~B}$ & 13,64 & 1,25 & 1,09 & 1,17 \\
\hline C.V. $(\%)$ & & & 38,50 & & & 38,60 \\
\hline
\end{tabular}

1/ Médias seguidas por letras diferentes minúsculas nas colunas e maiúsculas nas linhas diferem pelo teste $\mathrm{F}$, a $5 \%$ de probabilidade.

TABELA 7 - Produção de massa fresca e seca das plantas de almeirão, cultivadas sob três e quatro linhas por canteiro, em cultivo solteiro e consorciado, na primeira e segunda colheitas. Dourados, UFMS, 2003.

\begin{tabular}{|c|c|c|c|c|c|c|}
\hline \multirow{3}{*}{$\begin{array}{l}\text { Número de linhas } \\
\text { por canteiro }\end{array}$} & \multicolumn{3}{|c|}{ Massa Fresca $\left(\mathrm{t} \mathrm{ha}^{-1}\right)$} & \multicolumn{3}{|c|}{ Massa Seca $\left(\mathrm{t} \mathrm{ha}^{-1}\right)$} \\
\hline & \multicolumn{3}{|c|}{ Colheita } & \multicolumn{3}{|c|}{ Colheita } \\
\hline & $\mathbf{1}^{\mathbf{a}}$ & $2^{\mathbf{a}}$ & Média & $1^{-\mathbf{a}}$ & $2^{\mathbf{a}}$ & Média \\
\hline 3 & 11,50 & 13,60 & $12,55 \mathrm{~b}^{\underline{1 /}}$ & 0,85 & 0,85 & $0,85 \mathrm{~b}$ \\
\hline 4 & 14,86 & 16,33 & $15,60 \mathrm{a}$ & 1,12 & 1,13 & $1,13 \mathrm{a}$ \\
\hline \multicolumn{7}{|l|}{ Tipo de Cultivo } \\
\hline Solteiro & 16,16 & 18,71 & $17,44 \mathrm{a}$ & 1,26 & 1,26 & $1,26 \mathrm{~b}$ \\
\hline Consórcio & 10,21 & 11,22 & $10,72 \mathrm{~b}$ & 0,71 & 0,72 & $0,72 \mathrm{a}$ \\
\hline Média & $13,19 \mathrm{~B}$ & $14,97 \mathrm{~A}$ & 14,08 & 0,99 & 0,99 & 0,99 \\
\hline C.V.(\%) & & & 18,4 & & & 26,2 \\
\hline
\end{tabular}

Ciênc. agrotec., Lavras, v. 29, n. 4, p. 775-785, jul./ago., 2005 
A maior renda bruta foi do consórcio $\mathrm{R}_{4} \mathrm{~A}_{3}$, tanto na primeira (Tabela 8) como na segunda colheitas (Tabela 9). Observa-se que para o produtor, o consórcio $\mathrm{R}_{4} \mathrm{~A}_{3}$ foi $\mathrm{o}$ melhor, já que poderia ter gerado incrementos monetários por hectare de $\mathrm{R} \$ 28.279,80$ e de $\mathrm{R} \$ 20.065,95$ na primeira colheita e $\mathrm{R} \$ 18.703,35$ e de $\mathrm{R} \$ 17.283,60$ na segunda colheita, em relação ao almeirão e à rúcula, sob cultivo solteiro com três linhas que foram os de menores rendas (Tabelas 8 e 9). Os valores obtidos para a RAE e para a renda bruta são coerentes com as citações de (SILVA, 1983) e de Sullivan (2003), de que o aumento da produtividade por unidade de área é uma das razões mais importantes para se cultivar duas ou mais culturas no sistema de consorciação, porque permite melhor aproveitamento da terra e de outros recursos disponíveis, resultando em maior rendimento econômico.

Em relação à efetividade do aproveitamento das rebrotas, observou-se que a melhor renda bruta da segunda colheita, no tratamento $\mathrm{R}_{4} \mathrm{~A}_{3}$, correspondeu a $84,27 \%$ da melhor renda bruta obtida na primeira colheita, no mesmo tratamento, em ciclo vegetativo de 17 dias menor. Portanto, pode ser recomendado o aproveitamento da rebrota.

TABELA 8 - Renda bruta da rúcula e do almeirão, em cultivo solteiro e consorciado, sob três ou quatro linhas, colhidos aos 52 dias após o semeio. Dourados, UFMS, 2003.

\begin{tabular}{|c|c|c|c|c|c|c|c|}
\hline \multirow{2}{*}{$\begin{array}{l}\text { Forma de } \\
\text { cultivo }\end{array}$} & \multirow{2}{*}{ Espécie } & \multirow{2}{*}{$\begin{array}{l}\text { Número } \\
\text { linhas }\end{array}$} & \multirow{2}{*}{$\begin{array}{c}\text { Massa fresca } \\
\left(\mathbf{t ~ h a}^{-1}\right)\end{array}$} & \multirow{2}{*}{ RAE } & \multirow{2}{*}{$\begin{array}{l}\text { Número } \\
\text { Maços* }\end{array}$} & \multicolumn{2}{|c|}{ Renda bruta $(\mathbf{R} \$)^{* *}$} \\
\hline & & & & & & Cultivo & Total \\
\hline \multirow{4}{*}{ Solteiro } & \multirow{2}{*}{ Rúcula } & 3 & 11,62 & 1,0 & 50.151 & $22.567,95$ & $22.567,95$ \\
\hline & & 4 & 18,37 & 1,0 & 79.284 & $35.677,80$ & $35.677,80$ \\
\hline & \multirow{2}{*}{ Almeirão } & 3 & 14,30 & 1,0 & 31.898 & $14.354,10$ & $14.354,10$ \\
\hline & & 4 & 18,01 & 1,0 & 40.174 & $18.078,30$ & $18.078,30$ \\
\hline \multirow{2}{*}{$\begin{array}{l}\text { Consórcio } \\
\mathrm{R}_{3} \mathrm{~A}_{4}\end{array}$} & Rúcula & 3 & 14,20 & \multirow{2}{*}{1,87} & 61.286 & $27.578,70$ & \multirow{2}{*}{$39.333,15$} \\
\hline & Almeirão & 4 & 11,71 & & 26.121 & $11.754,45$ & \\
\hline \multirow{2}{*}{$\begin{array}{l}\text { Consórcio } \\
\mathrm{R}_{4} \mathrm{~A}_{3}\end{array}$} & Rúcula & 4 & 17,45 & \multirow{2}{*}{1,56} & 75.313 & $33.890,85$ & \multirow{2}{*}{$42.633,90$} \\
\hline & Almeirão & 3 & 8,71 & & 19.429 & $8.743,05$ & \\
\hline
\end{tabular}

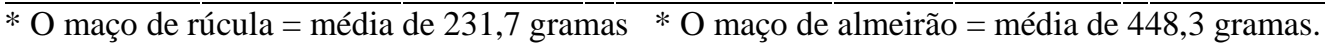

** Preço pago ao produtor: maço de rúcula $\mathrm{R} \$ 0,45$ e $\mathrm{R} \$ 0,45$ por maço de almeirão.

TABELA 9 - Renda bruta da rúcula e do almeirão, em cultivo solteiro e consorciado, sob três ou quatro linhas, colhidos aos 35 dias após o primeiro corte. Dourados, UFMS, 2003.

\begin{tabular}{|c|c|c|c|c|c|c|c|}
\hline \multirow{2}{*}{$\begin{array}{l}\text { Forma de } \\
\text { cultivo }\end{array}$} & \multirow{2}{*}{ Espécie } & \multirow{2}{*}{$\begin{array}{l}\text { Número } \\
\text { linhas }\end{array}$} & \multirow{2}{*}{$\begin{array}{l}\text { Massa fresca } \\
\left(\mathrm{t} \mathrm{ha}^{-1}\right)\end{array}$} & \multirow{2}{*}{ RAE } & \multirow{2}{*}{$\begin{array}{l}\text { Número } \\
\text { Maços* }\end{array}$} & \multicolumn{2}{|c|}{ Renda bruta $(\mathbf{R} \$)^{* * *}$} \\
\hline & & & & & & Cultivo & Total \\
\hline \multirow{4}{*}{ Solteiro } & \multirow{2}{*}{ Rúcula } & 3 & 9,6 & 1,0 & 41.433 & $18.644,85$ & $18.644,85$ \\
\hline & & 4 & 13,51 & 1,0 & 58.308 & $26.238,60$ & $26.238,60$ \\
\hline & \multirow{2}{*}{ Almeirão } & 3 & 17,16 & 1,0 & 38.278 & $17.225,10$ & $17.225,10$ \\
\hline & & 4 & 20,25 & 1,0 & 45.171 & $20.326,95$ & $20.326,95$ \\
\hline Consórcio & Rúcula & 3 & 11,06 & \multirow{2}{*}{1,76} & 47.734 & $21.480,30$ & \multirow{2}{*}{$33.937,20$} \\
\hline $\mathrm{R}_{3} \mathrm{~A}_{4}$ & Almeirão & 4 & 12,41 & & 27.682 & $12.456,90$ & \\
\hline Consórcio & Rúcula & 4 & 13,31 & \multirow{2}{*}{1,58} & 57.445 & $25.850,25$ & \multirow{2}{*}{$35.928,45$} \\
\hline $\mathrm{R}_{4} \mathrm{~A}_{3}$ & Almeirão & 3 & 10,04 & & 22.396 & $10.078,20$ & \\
\hline
\end{tabular}

* O maço de rúcula = média de 231,7 gramas * O maço de almeirão = média de 448,3 gramas.

** Preço pago ao produtor: maço de rúcula $\mathrm{R} \$ 0,45$ e $\mathrm{R} \$ 0,45$ por maço de almeirão. 


\section{CONCLUSÕES}

Sob o consórcio da rúcula e do almeirão, a produção de massa fresca do almeirão reduziu, porém, a da rúcula aumentou, tornando o consórcio eficiente quando se calculou a razão de área equivalente.

O aproveitamento da rebrota do almeirão foi viável.

O melhor arranjo de plantas, quanto à produtividade de massa fresca e renda bruta, foi de quatro linhas de rúcula e três linhas de almeirão $\left(\mathrm{R}_{4} \mathrm{~A}_{3}\right)$, na primeira e segunda colheitas.

\section{AGRADECIMENTOS}

Ao CNPq, pelas bolsas concedidas e à FUNDECTMS, pelo apoio financeiro.

\section{REFERÊNCIASBIBLIOGRÁFICAS}

BÜLL, L. T. Cultura do milho: fatores que afetam a produtividade. Piracicaba: POTAFOS, 1993.301 p.

CAETANO, L. C. S.; FERREIRA, J. M.; ARAÚJO, M. de. Produtividade da alface e cenoura em sistema de consorciação. Horticultura Brasileira, Brasília, v. 17, n. 2, p. 143-146, 1999.

CAMARGO, L. S. As hortaliças e seu cultivo. 3. ed. rev. Campinas: Fundação Cargill, 1992. 252 p.

FILGUEIRA, F. A. R. Novo manual de Olericultura: agrotecnologia moderna na produção e comercialização de hortaliças. Viçosa: UFV, 2000. 402 p.

GLIESSMAN, S. Broccoli and lettuce, intercropping in Califórnia,E.U.A. 1999. Disponível em: <http://agroecology.org/ cases/broclettuce.htm>. Acesso em: 1 maio 2004.

HEREDIAZÁRATE, N.A. Curvas de crescimento de inhame (Colocasia esculenta (L.) Schott), considerando cinco populações em solo seco e alagado. 1988. 95 f. Tese (Doutorado) - Universidade Federal de Viçosa, Viçosa, 1988.

HEREDIA ZÁRATE, N. A.; VIEIRA, M. C.; GRIEP, R. Produção dos clones de cará Liso e Caramujo conduzidos em forma rasteira e tutorada. Horticultura Brasileira, Brasília, v. 17, n. 1, p. 45-48, 1999.

HEREDIAZÁRATE, N. A.; VIEIRA, M. C.; WEISMANN, M.; LOURENÇÃO, A. L. F. Produção e renda bruta de cebolinha e de salsa em cultivo solteiro e consorciado. Horticultura Brasileira, Brasília, v. 21, n. 3, p. 578-581, 2003.

INNIS, D. Q. Intercropping and the scientific basis of the traditional agriculture. London: Intermediate, 1997.179 p.

KUNELIUS, H. T.; McRAE, K. B. Forage chicory persists in combination with cool season grasses and legumes. Canadian Journal of Plant Science, Ottawa, v. 897, p. 197200, 1998.

LARCHER, W. Ecofisiologia vegetal. São Carlos: RiMa Artes e Textos, 2000.531 p.

MÜLLER, S.; DURIGAN, J. C.; BANZATTO, D. A.; KREUZ, C. L. Épocas de consórcio de alho com beterraba (Beta vulgais L.) perante três manejos do mato sobre a produtividade e o lucro. Pesquisa Agropecuária Brasileira, Brasília, v. 33, n. 8, p. 1361-1373, 1998.

NOVO, M. C. S. S.; TRANI, P. E.; MINAMI, K. Desempenho de três cultivares de almeirão sob cultivo protegido. Horticultura Brasileira, Brasília, v. 21, n. 1, p. 84-87, 2003.

SALVADOR, D. J. Produção e renda bruta de cebolinha e de almeirão em cultivo solteiro e consorciado. 2003. $16 \mathrm{f}$. Monografia (Bacharelado em Ciências Biológicas) Universidade Federal do Mato Grosso do Sul, Dourados, 2003.

SANTAMARIA, P.; ELIA, A.; PAPA, G.; SERIO, F. Nitrate and ammonium nutrition in chicory and rocket salad plants. Journal of Plant Nutrition, Monticello, v. 21, n. 9, p. 17791789, 1998.

SILVA, N. F. Consórcio de hortaliças. In: VIEIRA, M. C. de; HEREDIAZÁRATE, N. A.; CASALI, V. W. D. Seminários de olericultura. Viçosa: UFV, 1983. v. 7, p. 1-19.

SRINIVASAN, A.; AHLAWAT, I. P. S. Growth and yield responses of short duration pigeonpea to intercropping with mungbean and sorghum, and to phosphate fertilization. 1990. Disponível em: <www.vtt.co.jp/staff/ ancha/jagcs.htm>. Acesso em: 3 set. 2003.

SULLIVAN, P. Intercropping principles and production practices. 2001. Disponível em: <www.attra.org/attra-pu/ intercrop.html\#abstratNational> . Acesso em: 3 set. 2003. 
TOLENTINO JÚNIOR, C. F.; HEREDIA ZÁRATE, N. A.; VIEIRA, M. C. Produção da mandioquinha-salsa consorciada com alface e beterraba. Acta Scientiarum: Agronomy, Maringá, v. 24, n. 5, p. 1447 1454, 2002.

VIEIRA, C. O feijão em cultivos consorciados. Viçosa: UFV, 1989. $134 \mathrm{p}$.
VIERA, M. C.; HEREDIAZÁRATE, N. A.; GOMES, H. E. Produção e renda de mandioquinha-salsa e alface, solteira e consorciados, com adubação nitrogenada e cama de frango em cobertura. Acta Scientiarum: Agronomy, Maringá, v. 25, n. 1, p. 201-208, 2003.

WHATLEY, J. M.; WHATLEY, F. R. Aluz e a vida das plantas. São Paulo: Pedagógica e Universitária, 1982. 101 p. 